\title{
What are the main obstacles for the shortage of nurses in the USA?
}

\begin{abstract}
Although many people would like to be a registered nurse, there is a shortage of nurses in the USA. Also, this country is projected to experience a shortage of nurses even more in the next few years. Due to those facts, this article aims to present a professional opinion about the main obstacles for the shortage of nurses in the USA. As main points it is presented that the USA population needs high quality nurses in appropriate quantities and people that want to become a nurse should be given the opportunity at a minimum to be admitted into the nursing program. However the manner in which nursing schools select prospective students and provide education must be reviewed, otherwise the shortage of nurses will continue to be a problem in the USA.
\end{abstract}

Volume 5 Issue 4 - 2018

De Oliveira Marcos Renato

Nursing Professor, Federal University of Piauí, Brazil

Correspondence: De Oliveira Marcos Renato, Nursing Professor, Federal University of Piauí, Brazil, Tel +55 3422-3003, Email enfmarcosrenato@hotmail.com

Received: May 14, 2018 | Published: July II, 2018

\section{Opinion}

There is a lot of discussion about the lack of nurses in the USA, and this country is projected to experience a shortage of nurses even more. ${ }^{1}$ Although many high-school students, who have the potential of being a nurse, see the nursing profession as honorable with respect and autonomy, and would like to go through this carrier path, ${ }^{2}$ it is known that, unfortunately, many baccalaureate nursing applicants who are denied admission under a rolling admission method may potentially be those who have the highest likelihood for success within the program. ${ }^{3}$ The nursing requirements for admission and the undergraduate nursing courses need to be reviewed. Otherwise, the lack of nurses in the USA will remain a major problem for this country.

The problems related to the lack of nurses in the market are the result policies in the nursing school, for example: excessive focus on memorization, lack of critical thinking instructional models, and oppressive methods of knowledge evaluation, that focuses on the collection of partial results, instead of the evaluation of the specific nursing competencies and abilities. At a time when the nursing profession needs more nurses, and perhaps more important, highly educated baccalaureate-prepared nurses, the admission policies that facilitate successful student and program outcomes are essential. ${ }^{3}$ Conversely a nurse will be expected to present abilities, such critical thinking, only $10 \%$ of the prerequisites for the nursing programs are related with critical thinking abilities, and the reaming $90 \%$ requirements are measured by students capacity to memorize due to that, $1 / 3$ of prospective students, give up on the program even when they are still taking prerequisite courses. In addition, according to a recent 2016-2017 report, nursing schools turned away 64,067 qualified applicants from the baccalaureate and graduate nursing programs in $2016 .{ }^{1}$ Also, among those students that were accepted, $60 \%$ usually drop out in the first year, due to school's policies. As a result, just in the last two years, approximately 592,536 students in the USA have given up their dreams of becoming a nurse.

The education model in the nursing schools needs to be seemed with the students' perspective as well. The present model has many critics and has not been capable of solving the main problem - the shortage of nurses, even if there is a desire for many to become one. Also, it has already been demonstrated that even though direct instruction can be conceived as a productive success compared to discovery learning, the analyses suggests that it may well be an unproductive success compared with examples of productive failure and productive success. ${ }^{4}$

As a result, students are exposed to pathological levels of stress. A descriptive study has proven that stress is very common in nursing education and it may have an impact on the psycho-social health of these students. ${ }^{5}$ The idealization of high grades at any cost, the excess of information, the requirement to memorize thousands of diagrams that will not be useful for a real patient care interaction, but are only necessary to prepare for school test, all of the above can be very frustrating for a student.

All of these issues, which a nursing student can go though, can be very dangerous for her/him and for others around them, depression and the risk of suicide among nursing students is very high. ${ }^{6}$

Other studies have proven that nursing student retention is a political and professional problem..$^{1,2,7}$ And that, collaboration between clinical placement providers, academic institutions, students and their families are required to address this issue. The illumination of factors that help students stay in the program may help educators to devise interventions that prevent future students from leaving.

Due to all those factors, I summon society, government, and the nursing schools to review the politics behind nursing admission and retention criteria. Indeed, the quality of care and patient security is a pillar of the overall nursing care that is supportive and must be kept under constant observation, when nursing education is involved. Also, agreeing with Dr. Martin Luther King Jr. “...The function of education is to teach one to think intensively and to think critically. Intelligence plus character - that is the goal of true education". 8 However, the methods of education and evaluation for prospective and nursing students have not been effective; otherwise the number of errors by nurses and their outcomes would not been happening as frequently as they are happening nowadays.

The USA population needs high quality nurses in appropriate quantities and people that want to become a nurse should be given the opportunity at a minimum to be admitted into the nursing program. However the manner how nursing schools select prospective students and provide education must be [re]viewed, otherwise the shortage of nurses and the quality of patient care will continue to be a problem in the USA. 


\section{Acknowledgments}

Professor Jennifer Decker, HCC.

\section{Conflict of interest}

The author declares that there is no conflict of interest.

\section{References}

1. Rosseter Robert. Nursing shortage. AACN online newsletter. 2014

2. Katz JR, Barbosa Leiker C, Benavides-Vaello S. Measuring the success of a pipeline program to increase nursing workforce diversity. Journal of Professional Nursing. 2016;32(1):6-14.

3. Newton Sarah E, Smith Laureen H, Moore Gary. Baccalaureate nursing program admission policies: Promoting success or facilitating failure?. $J$ Nurs Educ. 2007;46(10):439-444.
4. Kapur Manu. Examining productive failure, productive success, unproductive failure, and unproductive success in learning. Educational Psychologist. 2016;51(2):289-299.

5. Labrague Leodoro Jabien. Stress, stressors, and stress responses of student nurses in a government nursing school. Health Science Journal. 2014;7(4):424-435.

6. Aradilla-Herrero A, Tomás-Sábado J, Gómez-Benito J. Associations between emotional intelligence, depression and suicide risk in nursing students. Nurse Educ Today. 2014;34(4):520-525.

7. Iunes DH, Moura CC, Carvalho LC, et al. Predictors of Anxiety in College Students. Nurse Care Open Acces J. 2017;3(6):327-329.

8. King ML. The purpose of education. The Maroon Tiger. 1947. 